Abanico Agroforestal. Enero-Diciembre 2021; 3:1-13. http://dx.doi.org/10.37114/abaagrof/2021.7 Artículo Original. Recibido: 10/07/2021. Aceptado: 20/10/2021. Publicado: 17/11/2021. Clave:2021-18. https://www.youtube.com/watch?v=VWEI-v321SU

\title{
Estudio zoogenético de la gallina autóctona como una alternativa sustentable para las familias rurales del trópico mexicano
}

Zoogentic study of the autoctona hen as a sustainable alternative for rural families of the mexican tropic

\section{Blasco-Patiño Lisette ID, Nieto-Rosaliano Sergio ID, González-Salas Miguel ID, Cabrera-Núñez Amalia ${ }^{* I D}$, Lammoglia-Villagomez Miguel ID , Martínez-Sánchez César ${ }^{\mathrm{ID}}$, Montero-Solís Flor ID}

Universidad Veracruzana, Facultad de Ciencias Biológicas y Agropecuarias, Veracruz, México. *Autor responsable: Amalia Cabrera Núñez. ${ }^{* *}$ Autor de correspondencia Km. 7.5 Carretera Tuxpan -Tampico, Colonia Universitaria. C.P. 92860. Tuxpan, Veracruz, México. lisette12bp@gmail.com, senieto@uv.mx, miguegonzalez@uv.mx, amacabrera@uv.mx, malammoglia@uv.mx, cesamartinez@uv.mx, flmontero@uv.mx

\section{RESUMEN}

El objetivo de la investigación fue evaluar el estudio zoogenético de la gallina autóctona del trópico mexicano. Para ello, se aplicó una encuesta sobre las comunidades que producen gallinas autóctonas adultas de 12 meses de edad (hembras y machos). Esta investigación se desarrolló en tres comunidades rurales del municipio de Nautla, Veracruz; Isla de Chapachapa, la Unión (El poblado) y Cerro Dos Hermanos. Las comunidades fueron seleccionadas por el acceso a sus viviendas para facilitar la recolección de la información de 80 gallinas. Se tomaron en cuenta las siguientes variables: como se le conoce al ave en la comunidad, origen, distribución, características de la raza, descripción genética y sus características productivas. Se aplicó estadística descriptiva para determinar la dispersión de los datos cualitativos y cuantitativos, empleando un análisis de varianza, seguido de un análisis de correlación y regresión. Los colores de plumajes más comunes en las comunidades del estudio, fueron negro, rojo y abada, que es como comúnmente se les llamaban a las aves con un color de plumaje moteado (negro con blanco). No obstante, se encontraron coloraciones poco comunes, que eran resultado de mutaciones y cruzamientos naturales.

Palabras clave: Gallinas autóctonas, zoogenético, sustentable, familias rurales, trópico.

\begin{abstract}
The objective of this research was to evaluate the zoogentic study of the autochthonous hen of the Mexican tropic. For this purpose, a survey was applied to communities that produce 12-month-old adult native hens (females and males). This research was carried out in three rural communities in the municipality of Nautla, Veracruz; Isla de Chapachapa, La Unión (El Poblado) and Cerro Dos Hermanos. The communities were selected because of their access to the land. The communities were selected by access to their dwellings to facilitate the collection of information from 80 hens. The following variables were taken into account: how the bird is known in the community, origin, distribution, breed characteristics, genetic description and productive characteristics. Descriptive statistics were applied to determine the dispersion of qualitative and quantitative data, using analysis of variance, followed by correlation and regression analysis. The most common plumage colors in the study communities were black, red and abada, which is what birds with a mottled plumage color (black with white) were commonly called. However, uncommon colorations were found, which were the result of mutations and natural crosses.
\end{abstract}

Keywords: Native hens, zoogenetic, sustainable, rural families, tropics. 


\section{INTRODUCCIÓN}

En los últimos años la FAO (2013) busca disminuir el hambre y mala nutrición a través de alimentación y agricultura que contribuyan a mejorar las condiciones de vida, en especial de los más vulnerables de forma económica, social y ambiente sostenible. Para focalizar medidas encaminadas a la consecución de sus metas mundiales de seguridad alimentaria, eliminación de la pobreza y gestión. Utilizando los recursos naturales de los países miembros a identificar y aplicar políticas, estrategias y tecnologías que contribuyan a un suministro sostenible y más adecuado de productos y servicios de la agricultura, la actividad forestal y la pesca (Foresight, 2011).

El principal enfoque de la FAO (2013) es lograr un nivel ecosistémico de la pesca y la acuicultura bajo denominativo Ahorrar para Crecer. El programa marcó la intensificación de la producción sostenible de cultivos, la agenda global para una ganadería sostenible, la gestión sostenible de los bosques, la alianza para una agricultura climáticamente renovables y la iniciativa es afrontar la escasez de agua, adoptados en diversos grados por los países. Es hora de aprovechar el rico acervo de conocimientos y experiencia adquiridos a través de esos programas para elaborar una visión común y un enfoque integrado para la sostenibilidad en las esferas de agricultura, actividad forestal y pesca (Naciones Unidas, 2015).

Además de atender las necesidades básicas de alimentos, piensos, fibras y combustible que experimenta la humanidad, el sector de la alimentación da empleo a uno de cada tres de los trabajadores del mundo y proporciona medios de subsistencia a familias rurales formadas por un total de 2500 millones de personas (FAO, 2013). Dicho sector contribuye a la cohesión social en las zonas rurales y preserva las tradiciones y el patrimonio cultural (Van Huylenbroeck et al., 2007).

Algunos autores han desarrollado estudios, demostrando que las proyecciones, de la población mundial, que asciende actualmente a alrededor de 7200 millones de personas, llegará a 9300 millones en el año 2050 (Naciones Unidas, 2015). Ese crecimiento demográfico y los cambios dietéticos previstos vinculados al aumento de los ingresos y los actuales niveles de consumo, indican que a más tardar en 2050 la producción agrícola mundial tendrá que aumentar un $60 \%$ y un $100 \%$ en los países en desarrollo, para atender la demanda. En el pasado, la innovación tecnológica y las mejoras institucionales dieron lugar a un considerable aumento de la producción y la productividad (Wheeler \& Von Braun, 2013).

La avicultura familiar es una actividad mundial y se estima que gran parte de las comunidades rurales la practica, contribuye a un elemento estratégico para la seguridad alimentaria por su aporte de proteína de alto valor biológico y aporte económico. Además de contar con una amplia variedad genética de gallinas domésticas que ayudan a la adaptabilidad de cada ejemplar para una mayor producción y alta resistencia a enfermedades (Villacís Rivas et al., 2016). En este sistema sustentable las aves son criadas en los traspatios, su cuentan con alrededor de 10 a 30 gallinas por vivienda, se les alimentan con sobras y pequeñas cantidades de otros alimentos. Las mujeres y los niños suelen ser los encargados de la gestión de las parvadas de la familia (Juárez, 2008). 
En las comunidades rurales la selección sucede de manera natural y son los avicultores quienes hacen esta selección en base a las características fenotípicas de las aves de traspatio. Hoy en día se ha perdido gran parte de estos conocimientos incluídos el manejo de estas aves en los corrales, el volver a incluir a la avicultura de gallinas criollas es de suma importancia tanto para la economía de familias campesinas como para la implementación de alimentos saludables y de excelente calidad nutricional (Lázaro et al., 2012). Por lo anterior esta investigación tiene como objetivo realizar el estudio zoogenético de la gallina autóctona como una alternativa sustentable para las familias rurales del trópico mexicano.

\section{METODOLOGÍA}

Para la elaboración de este trabajo, se aplicó una encuesta sobre las comunidades que producen gallinas autóctonas adultas de 12 meses de edad (hembras y machos). Dichas comunidades fueron seleccionadas, por el acceso a sus viviendas para facilitar la recolección de muestras. Los datos obtenidos, se basaron en el tipo de alimentación, fin zootécnico de las gallinas y selección de ejemplares. Se implementó un formato, en el cual se registraron las características fenotípicas y de producción. Se realizaron en total de 8 vistas en las tres comunidades seleccionadas para el estudio del municipio de Nautla, Veracruz. Caracterización Zoométrica. Cada gallina autóctona muestreada eran adultas (hembra y macho) nacidos en el mismo lugar o adquiridas en diferentes comunidades, en total se observaron 80 gallinas entre los tres municipios, tomando en cuenta las siguientes variables: nombre como se le conoce en la comunidad, origen, distribución, características de la raza, descripción genética y características productivas. Se aplicó la estadística descriptiva para determinar la dispersión de los datos cualitativos o cuantitativos, empleando un análisis de varianza, seguido de un análisis de correlación y regresión.

\section{RESULTADOS Y DISCUSIÓN}

En los resultados encontrados se describen las características fanerópticas que abarca caracteres visibles como es: piel, pelo, plumaje, color (Juárez, 2008; Alexi et al., 2017).

Según Cadenas et al. (2015), en primer lugar, el color de la piel está determinado por el gen -w- "piel amarilla". Esto también da el color amarillo al pico y las patas que es como comúnmente se les conoce a los miembros inferiores de las aves de traspatio. Característica que es transferida por los genes como una importante herencia. La coloración de la piel se denota debajo de la piel (Barzola, 2015).

El color del plumaje se ve afectado por una gran variedad de genes, además existen genes modificadores que no son bien conocidos, incluso algunas razas, es muy común clasificarlas por el color de su plumaje (Macri et al., 2019). La herencia de estos genes no es igual en la distribución del color en todas las partes del cuerpo, lo que complica aún más la identificación del mapa genético del color, incluso existen genes cuyo efecto es determinar la distribución del color en cada pluma. 


\section{1.- Gallus domesticus L. subespecie inauris n.I "aretona"}

Nombres locales: Santandereana, ecuatoriana, chilena, De aretes, Araucana, gallina de los huevos de pascua, Collonca de aretes. Centro de origen: América del sur. Distribución: Nacional. Características de la raza: Pose abundante plumaje alrededor de la cara y el oído que, simulan aretes, carece de glándula uropigiana, debido a la falta de vértebras coccígeas. Estas aves provienen de huevos de cáscara azul. Descripción genética: El color azul del huevo, constituye a una mutación autosómica dominante, e segregada totalmente a la cáscara blanca. Características productivas: Los ejemplares machos llegan a un peso de 3 kilogramos y las hembras de 2.5 kilogramos, los huevos con cáscara de color azul tienen un peso máximo de 70 gramos.

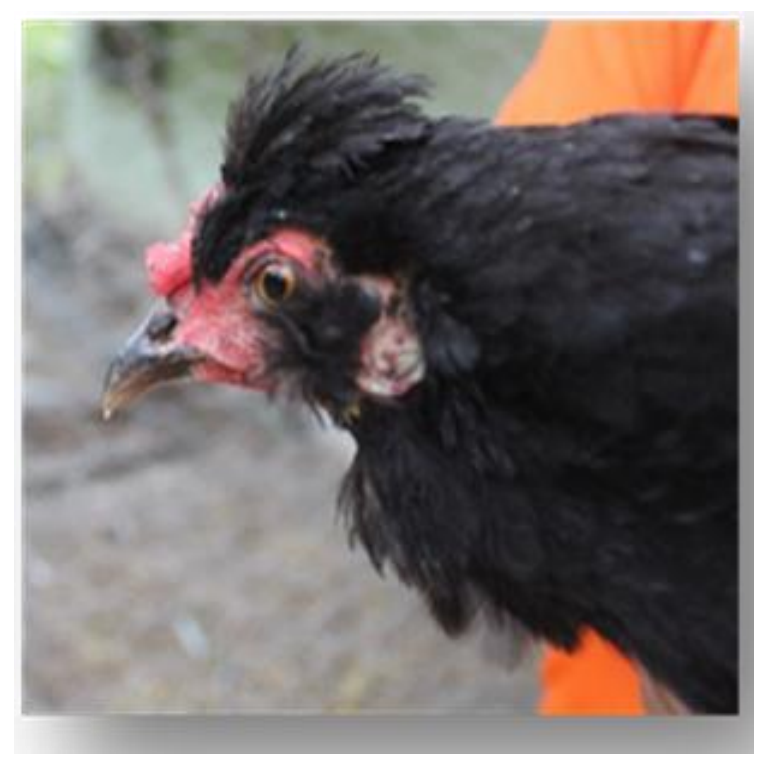

Figura 1.- Ejemplar inauris

\section{2.- Gallus domesticus L. subespecie barbatus n.I. "barbuda"}

Nombres locales: Tufus, barbada, tufa. Centro de origen: Asia. Distribución: Nacional.

Características de la raza: Cuenta con abundante plumaje en ambos lados de la región auricular y alrededor de la cara, simulando una barba compacta, con patillas a los lados. Se observa variaciones en el color del plumaje y los huevos suelen ser de color marrón. Descripción genética: La característica del plumaje se deben a un gene autosómico dominante, llamado $M b$. Características productivas: Los individuos poseen un peso para los machos de 2.5 kilogramos y 2.0 kilogramos para las hembras, los huevos con un peso máximo de 55 gramos y la postura oscila entre 120-150 huevos por año.

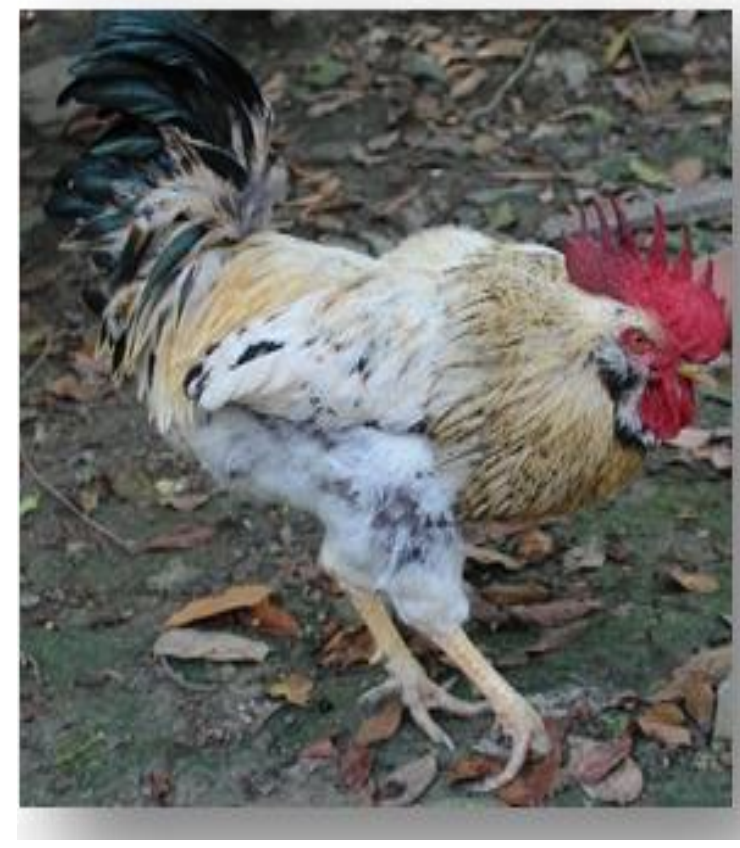

Figura 2.- Ejemplar barbatus 


\section{3.- Gallus domesticus L. subespecie ecaudatus n.I "bolita"}

Nombres locales: Tapuncha, tapa, récula, francolina. Nombres en inglés: Rumpless Fowl, Rumpkin, Persian Cock. Centro de origen: Asia. Distribución: Nacional. Características de la raza: La falta de rabadilla en aves, es una variación hereditaria, que consiste en la carencia de 14 a 16 plumas rectrices caudales, dichas aves parecen más recogidas, cortas y esféricas. El color del plumaje es muy variado, el color de los huevos es marrón. Descripción genética: Este gene dominante, se denomina "Rp", el cual es hereditario y la falta de rabadilla es del tipo intermedio. Debido a genes modificadores estos causan, que las vértebras se fusionan. Características productivas: Los machos de esta raza llegan a pesar hasta 2.0 kilogramos, y para las hembras llegar a un peso aproximado de 1.5 kilogramos y los huevos con un peso de 58 gramos.

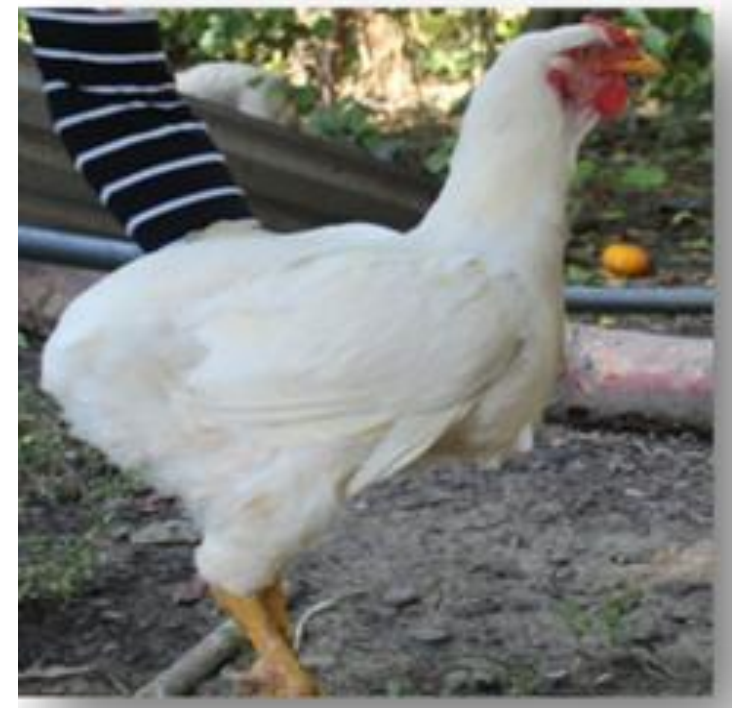

Figura 3.- Ejemplo ecaudatus

\section{4.- Gallus domesticus L. subespecie nidícolas n.I "guinicas"}

Nombres locales: Carioca, cuello desnudo, cuelli pelada. Nombres en inglés: TurkensNaked Necks. Centro de origen: Asia. Distribución: Nacional. Características de la raza: Es considerada una mutación en la distribución de las plumas. Estos ejemplares no solo carecen de plumas al trayecto inferior de la cabeza, si no, que no existen, salvo la parte más próxima a la cresta, que quiere decir que carece también de folículos. En la parte dorsal del cuello carece de plumas, excepto la parte al trayecto espinal anterior. Se puede observar la piel desnuda del cuello, la cual se torna rojiza al llegar a la madurez sexual. El color del plumaje es variado, y referente a los huevos son de color marrón. Descripción genética: La variación del cuello desnudo, se debe a un gene dominante, "Na", siendo ejemplo de la diferenciación de una raza por un solo. Características productivas: El peso para los machos es de 2.5 kilogramos, en hembras alcanzando un peso aproximado de 2.0 kilogramos y el peso de los huevos es de 70 gramos.

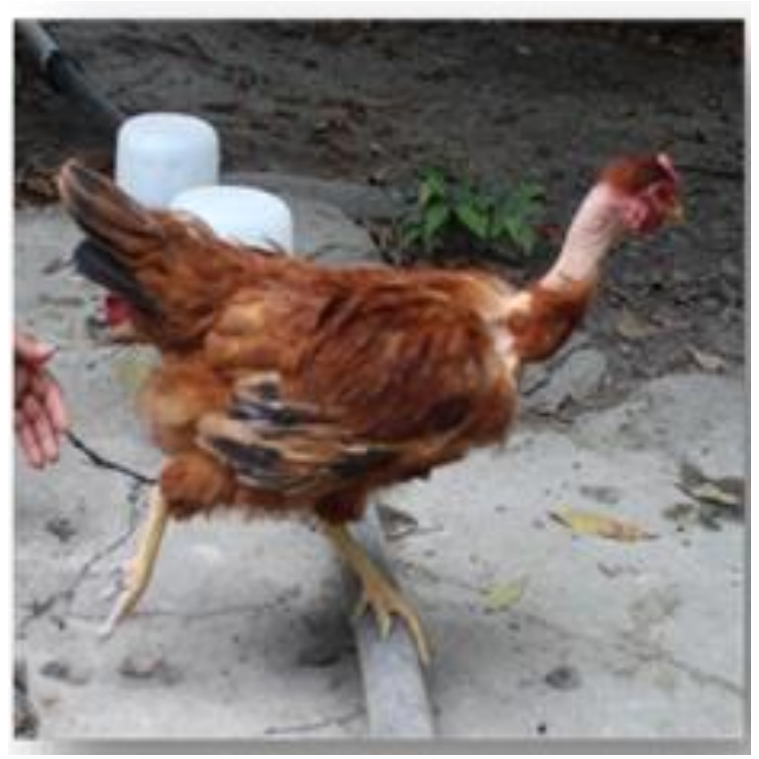

Figura 4.- Ejemplar nidícolas 


\section{5.- Gallus domesticus L subespecie crispus. n.I "rizada"}

Nombres locales: Chusca, Crespa, Chiroza, Churrumba, Chirapa, Rizada, Trintre.

Centro de origen: Asia. Distribución: Nacional. Características de la raza: El plumaje de las gallinas tiene un aspecto como "rizado", de ahí el peculiar nombre de "gallina rizada", es una variación en la estructura de las plumas, se caracteriza porque las plumas exteriores, de cabeza, cuello, tronco y alas están curvadas hacia adelante, desde la punta y retorcidas o enrolladas en una o varias veces, pareciendo crespo y esponjoso. El plumaje suele ser de color variado y en el caso de los huevos son de color marrón. Descripción genética: El plumaje rizado se debe a un gene autonómico parcialmente dominante con un modificador autonómico recesivo, "mf". Esta característica es difícil poder mantenerla en las razas criollas, debido a la variedad de genes que existe en un solo corral, a causa de las cruzas. El gen modificador, si estuviera en un ambiente controlado como en sistemas estabulados, donde solo abunda un tipo de, sería considerado la clase que preservaría y acumularía en la selección natural. Características productivas: El peso de los ejemplares machos es de aproximadamente 2.5 kilogramos y el de las hembras presentan un peso de 2.0 kilogramos. El color de los huevos es variado desde blanco a marrón, con un peso de 70 gramos.

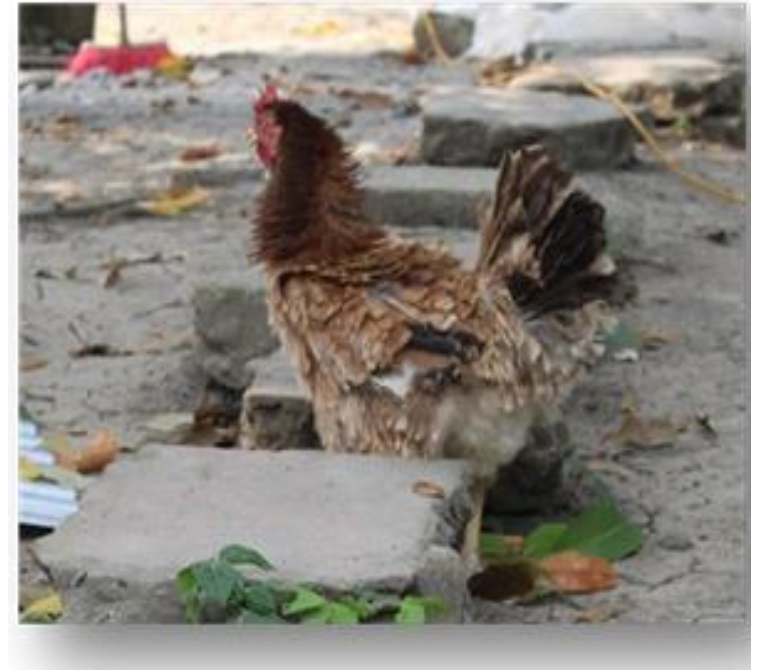

Figura 5.- Ejemplar crispus

\section{6.- Gallus domesticus L. subespecie pugnax n.I "gallina fina"}

Nombres locales: Gallina Fina o De pelea. En ingles: Old English game. Centro de origen: Asia (India). Distribución: Nacional. Características de la raza: Se tiene muy poca información registrada, se observan ejemplares con un color del plumaje variado y los huevos suelen ser de color blanco. Descripción general: Estas aves son muy similares a su tronco de origen, provenientes del Gallus bankiva. Los ejemplares machos, se fueron seleccionando para la "peleas de gallos", debido a su complexión y temperamento, las hembras por otra parte se llevan el título de excelentes incubadoras y presentan la mejor habilidad materna.

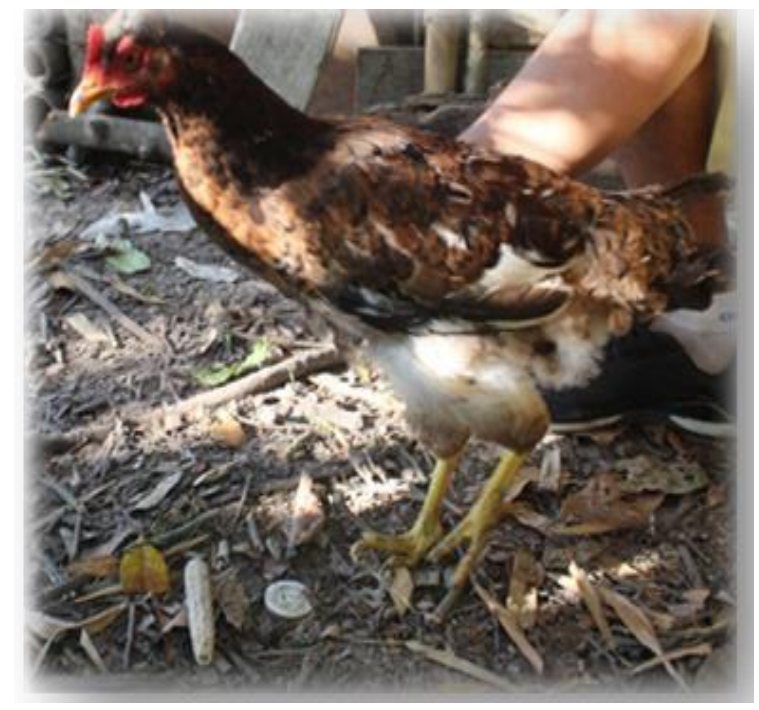

Figura 6.- Ejemplar pugnax 


\section{7.- Gallus domesticus L. subespecie gigantes n.I "calzada"}

Nombres locales: Zamarrona, calzada. En inglés: Cochins, Brahmas, langshan. Centro de origen: Asia Distribución: Nacional. Características de la raza: La distribución de las plumas se encuentra en las patas y dedos. Se hace más abundantes a lo largo del borde externo del tarso-metatarso y en la falange más exterior. El color del plumaje es variado y los huevos son de color marrón. Descripción genética: Aun no existen estudios genéticos que comprueben la causa de la mutación. Las aves "Ptilopodia" son clasificadas por la característica del plumaje en las patas, comúnmente se les llama "patas calzadas", esta raza se obtiene del cruzamiento de aves ptilopodas y aves sin plumas en las patas, denominada "generación F1". En algunos casos, existen animales jóvenes que carecen de uña y de algunas de las falanges del dedo. Características productivas: Los machos poseen un peso corporal máximo de hasta $3.0 \mathrm{Kg}$ y para las hembras con un peso de 2.5 kilogramos y los huevos de los ejemplares hembra son de un peso máximo de 60 gramos.

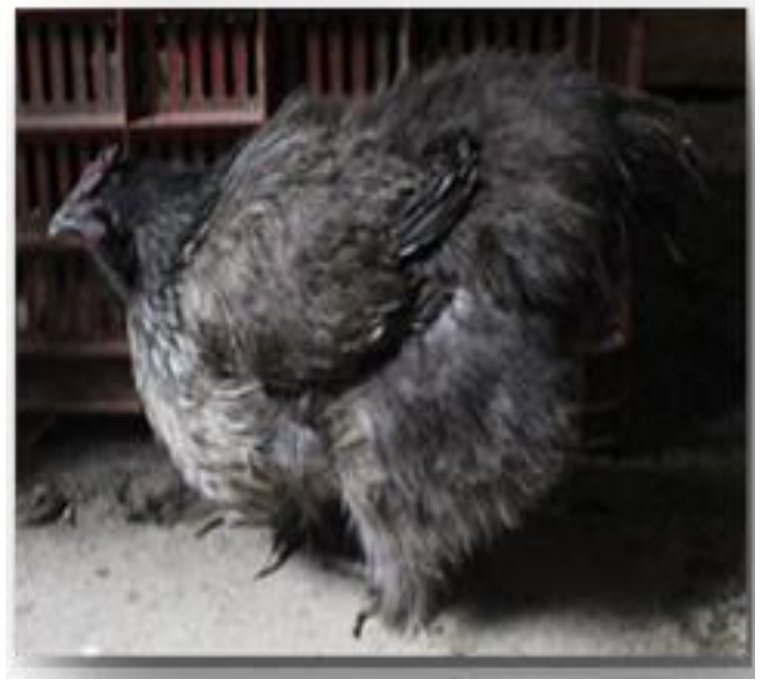

Figura 7.- Ejemplar gigantes

\section{8.- Gallus domesticus L. subespecie cristatus n.I "copetona"}

Nombres Locales: Copetonas, Copetudas, Moñudas. Centro De Origen: Asia y Europa, con presencia en América del Sur. Distribución: Nacional. Características De La Raza: Esta variación se logra a la longitud de las plumas y a que algunas plumas de la cabeza son extremadamente largas, casi erectas, que, en vez de permanecer pegadas en la cabeza, se distribuye formando un penacho. Las plumas que caen sobre los ojos, tapando el rostro. El color del plumaje puede ser variado, y el color de los huevos es marrón. Descripción Genética: El "copete" es provocado por un gene autosómico parcialmente dominante, "Cr", es un carácter hereditario dominante. Está muy ligado al rizado, blanco dominante y presencia de hernia en ejemplares homocigotos. Características Productivas: Con un peso para los machos de 2.0 kilogramos, para las hembras 1.5 kilogramos y el peso de los huevos son 55 gramos.

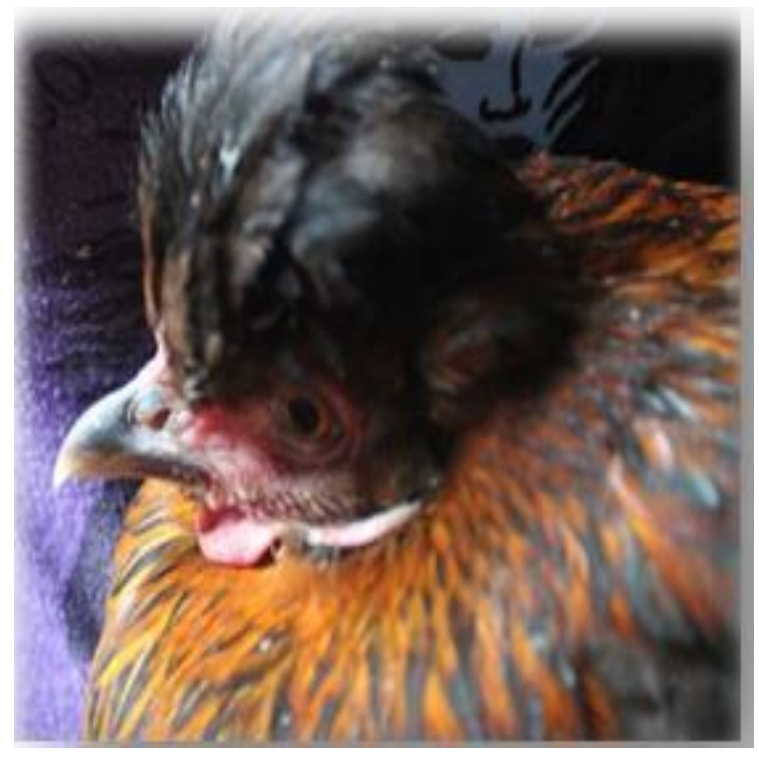

Figura 8.- Ejemplar cristatus 


\section{9.- Gallus domesticus L. subespecie morio n.I "colorada"}

Nombres locales: Nicaragua, Mora, etíope. Presencia en América del Sur, pero sin reportes precolombinos. Nombres en inglés: Black Fowl. Características de la raza: La fibromelanosis es la pigmentación melánica del tejido conjuntivo, que está presente en estas aves. Se encuentra en la dermis de la piel, los músculos, nervios, en los tendones, y paredes de los vasos sanguíneos, en la dura y piamadre del cerebro. Descripción genética: Fibromelanosis se considera que es inhibida por un gene ligado al sexo, investigadores creen que puede ser idéntico al gen "Id", que inhibe la melanina dérmica ligado con el mismo. Cuando se dan los cruzamientos, por la acción del inhibidor, todas las aves F1 tienen la piel negra. Características productivas: Las hembras poseen un peso máximo de 1.5 kilogramos, los machos alcanza 2.0 kilogramos aproximadamente, ya que varían en esta proporción y los huevos con un peso de 45 gramos.

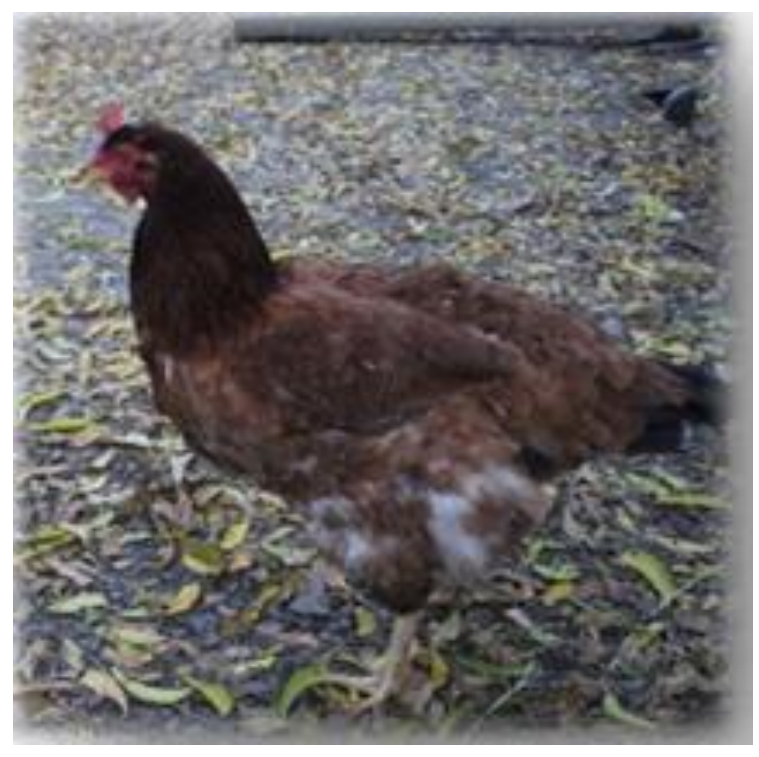

Figura 9.- Ejemplar morio

10.- Gallus domesticus L. subespecie nanus

Nombres locales: Cubana normal, kika normal, kike normal. Centro de origen: Asia y Europa (Alemania). Con presencia en América del Sur, sin reportes precolombinos.

Distribución: Nacional. Características de la raza: Esta raza pose un tamaño de su cuerpo pequeño, muy similar al anterior, su característica más peculiar es en el color de sus huevos. El color en su plumaje es variado y los huevos van desde el color blanco hasta el tan aclamado color "azul o verde", aunque también se presentan caso de diferentes tonalidades. Descripción genética: La reducción del tamaño suele asociarse al sexo, estas aves poseen una cantidad menor de genes con efectos acumulativos para tamaño corporal, a comparación de las razas grandes y medianas. Se han encontrado genes dominantes ligados al sexo reductor del tamaño corporal, en el cruzamiento entre machos de las razas Bamtams Sebright (cubanos), y hembras Brahma Ligera (de tamaño normal). Características productivas: Los machos llegan alcanzar un peso máximo de 1.0 kilogramos y mientras que las hembras pesar alrededor de 750 gramos y el peso de los huevos es de 40 gramos.

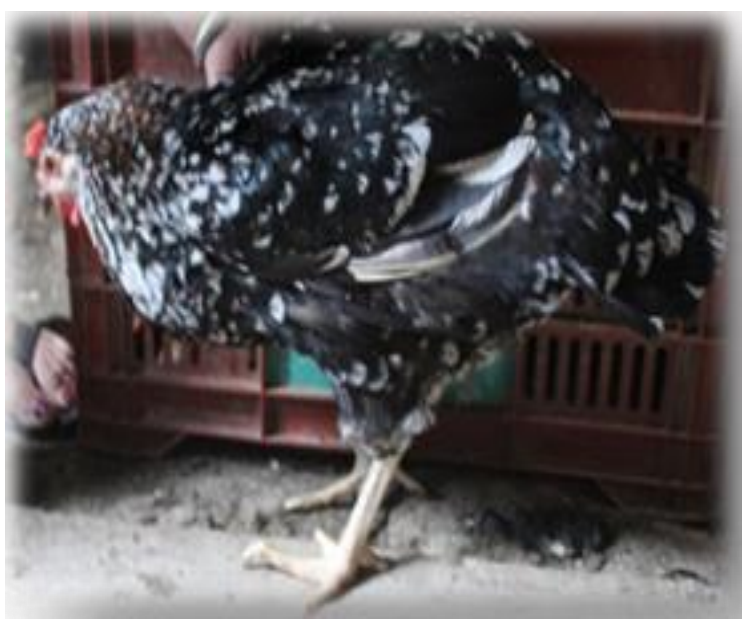

Figura 10.- Ejemplar nanus 


\section{1.- Gallus domesticus L. subespecie dorkingensis n. I "currita"}

Nombres locales: Paticorta, Enana, Reptadora. Centro de origen: Asia, Inglaterra, Alemania. Distribución: Nacional. Características de la raza: Esta variación se genera en el esqueleto apendicular, el tamaño del cuerpo es normal, pero los huesos largos de las extremidades posteriores están acortados. El hueso más afectado de todos es la tibia, el peroné de la raza Creeper es más grueso. El color del plumaje estos ejemplares son variado y pone huevos de color marrón. Descripción genética: Gracias a la mutación, "Cp", que es quien produce la anomalía en los heterocigotos. En el caso de los ejemplares homocigotos generalmente suele ser fatal. En las razas llamada reptadores, este gen hace que sus patas y alas estén acortados, deformando su manera de caminar, al aparearse estas aves, sus crías mueres al cuarto día aproximadamente, ya que sus miembros posteriores están casi pegados al cuerpo y solo, unos cuantos logran sobrevivir. Estos genes dominantes causan que, en ejemplares heterocigotos, se produzcan anormalidades físicas y en homocigotos causen muerte embrionaria. Características productivas: Con un peso máximo en los machos de 2.5 y las hembras es de 2.0 kilogramos, el peso de sus huevos es de 60 gramos.

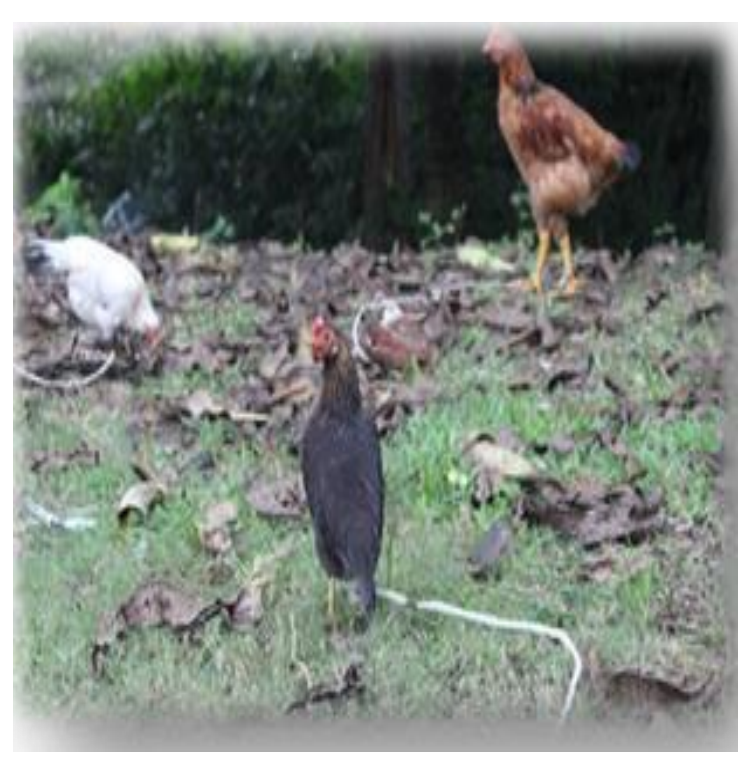

Figura 11.- Ejemplar dorkingesis

El color del plumaje de las gallinas está determinado por dos tipos de pigmentos, los cuales son: Eumelaninas y feomelaninas. Las eumelaninas son responsables del color negro y azul-grisáceo, y las feomelaninas lo son del rojo, pardo y leonado. Pero el gen multialeico más importante para el color del plumaje de las gallinas es el "E", encargado de la extensión del color negro y presencia de aperdizados en las hembras, además de diferencias en el color de los pollitos recién nacidos (Cadenas et al., 2015). Existen 7 alelos que se enlistan de mayor a menor por su dominancia: El alelo $E$ produce aves totalmente negras en ambos sexos. El alelo ER "Abedul", produce aves negras, pero existen zonas que no son del todo negras, especialmente en cuello y cabeza, en ambos sexos, es decir, sin dimorfismo sexual respecto al color. Los genes e son 5 y provocan un marcado dimorfismo sexual. Todos ellos son recesivos respecto a E y a ER y entre sí existen diferentes grados de dominancia (Jáuregui et al., 2012).

Los machos con el gen "e", presentan el plumaje tipo "silvestre", que no es más que el color negro básico, pero con coloración rojiza-amarillenta en esclavina, silla y punta del ala (Revelo et al., 2017). Para las hembras "e" es muy diferente, ellas presentan los siguientes tipos de plumaje: ewh "Wheaton", esclavina marrón rojizo intenso, dorso marrón con discretas marcas negras o grises, alguna pluma negra en la cola y vientre y pechuga de color crema muy claro, casi blanco. e+ "wild type", dorso gris muy oscuro y 
aperdizado con motas finas, esclavina con briznas amarillas y pecho asalmonado eb "Brown", todo el cuerpo pardo, con marcas abundantes de aperdigado, esclavina con briznas amarillas ebc "Buttercup", semejante al anterior, pero más amarillento y marcas de aperdigado más señaladas. eY es el más recesivo de todos y presenta color semejante al Wheaten (Jáuregui et al., 2012).

Silver -S- El gen está ligado al sexo, al aparecer el alelo dominante -S- inhibe la producción de pigmento rojo - feomelaninas-, esto provoca que las plumas no negras se tornen a un color blanco, sin tener efecto sobre los pigmentos negros - eumelaninas(Cadenas et al., 2015). Azul -BI- El gen es un diluyente del pigmento negro, cuando se presenta de forma homocigotica dominante diluye casi por completo el color negro, así las plumas que eran negras toman un color blanco sucio o gris. En heterocigosis -Bl bllas plumas negras pasan a ser gris-azuladas (Campos, 2014). Blanco dominante -IEs un gen que provoca con su aparición, la inhibición de la formación del pigmento negro, y además reduce la del rojo, los pollitos son amarillos. Lleva el gen W+ y un alelo especial (id) para pigmentación de melanina dérmica en las patas (Campos, 2014).

Blanco recesivo -c- Es un gen autosómico recesivo, cuyo homocigoto -cc- da lugar a animales totalmente blancos, con pollitos amarillos o blanco grisáceos. El dominante -Cpermite la expresión del color básico (Cigarroa et al., 2013). Gen aperdizado -Pg-

Este gen solo se manifiesta en hembras de genotipo "eb", dando lugar a un triple bandeado de las plumas, presenta una capa color marrón con negro, en machos, es con mucho más negro (Campos, 2014). Gen bordeado - Lg- Produce un borde negro en la pluma y el resto se torna blanco, salvo si está presente el gen "s", en cuyo caso el resto sería dorado. Según (Campos, 2014), también es conocida como "negra barrada", el color de las patas es debido a un alelo dominante (W). Gen lentejuelado -Sp-. Se origina una mancha negra en el extremo de la pluma, formando una "V". A igual que el caso anterior, el resto de la pluma sería dorado o blanco según esté o no presente el gen "s", lucen algunas briznas café amarillentas, pareciendo un triángulo del ala y de la cola es de color blanco (Tovar et al., 2014). Gen moteado -mo-. Gen recesivo cuya presencia determina que en el vértice de la pluma se presente una mancha negra en forma de "V", pero en este caso, se elimina el pigmento en el ápice, con lo que produce una pluma oscura con la punta blanca (Revelo et al., 2017).

A lo largo de los años, la avicultura moderna con sus líneas de gallinas mejoradas, tomo mayor importancia, debido a su alta productividad en poco tiempo (8 semanas) de huevo y/o carne, de tal manera que la gallina autóctona no puede competir. Pero sorprendentemente, sigue con mayor peso en dichas comunidades donde se sigue implementando la selección de ejemplares criollos, por su rusticidad y resistencia a enfermedades. Mientras otros buscan la manera de eliminar la cloquera en las gallinas, las comunidades rurales, buscan obtener aves que se reproduzcan de forma natural, garantizando la seguridad alimentaria para sus familias (Sonaiya et al., 1999).

Además de obtener los huevos, que son una alta fuente de proteína, también son utilizados para ser incubados y así, conservar los genes de la estirpe. Desde la domesticación de las gallinas autóctonas, se han observado distintas mutaciones, que van caracterizando a cada raza en particular, los cambios que se realizan en el plasma 
germinal, provocan ciertas alteraciones que son reflejadas en el fenotipo o aspecto de las gallinas. Algunos ejemplares no presentan dicha mutación, debido a que portan un gen recesivo, esto significa que el cambio en un solo gene no producirá un efecto visible hasta que no se emparejen dos aves portadoras de la misma mutación (Valencia, 2009).

\section{CONCLUSIONES}

En las comunidades rurales visitadas del trópico el fin zootécnico de las gallinas autóctonas es para autoconsumo y los excedentes para la venta de carne y huevo. Los colores de plumajes más comunes en las comunidades del estudio, fueron el negro, rojo y abado (plumaje moteado de negro con blanco. Además, se encontraron coloraciones poco comunes resultado de mutaciones y cruzamientos naturales.

\section{LITERATURA CITADA}

ALEXI E, Ormaza L, Yenny DC, Navarrete T. 2017. Caracterización fenotípica y morfológica de una población autóctona de la gallina criolla (gallus domésticus I). Universidad Técnica Estatal de Quevedo Facultad de Ciencias Pecuarias cantón Pichincha Provincia de Manabí. Proyecto de investigación. Ecuador. Universidad Técnica Estatal de Quevedo.

https://1library.co/document/zx5gpkdq-caracterizacion-fenotipica-morfologica-poblacionautoctona-domesticus-pichincha-provincia.html

BARZOLA D. 2015. Características morfológicas y fenotípicas de gallinas criollas (gallus domesticus) en la parroquia manglaralto de la provincia de Santa Elena. https://repositorio.upse.edu.ec/handle/46000/2260

CADENAS O, Bahamonde VD, Cisneros H, Buitrón G. 2015. Alteraciones de coloración en el plumaje de aves silvestres del Ecuador. ACl Avances En Ciencias e Ingenierías. 7(2). https://doi.org/10.18272/aci.v7i2.259

CAMPOS J, García M. 2014. Razas españolas de gallina. Ministerio de Ciencia y Tecnología. Instituto Nacional de Investigación y Tecnología Agriaría y Alimentaria. Madrid, España.

http://wwwsp.inia.es/Investigacion/Departamentos/MGA/GI/MejGenGallinas/Documents/ gallinas.pdf

CIGARROA VF, Herrera G, Ruiz S, Cuca GJ M, Rojas MRI, Lemus FC. 2013. Caracterización fenotípica del guajolote autóctono (Meleagris gallopavo) y sistema de producción en la región centro norte de Chiapas, México. Revista Agrociencia. 47(6): 579591. ISSN 1405-3195.

http://www.scielo.org.mx/pdf/agro/v47n6/v47n6a5.pdf 
FAO. 2013. Cría de aves de corral, un salvavidas para los campesinos rurales. http://www.fao.org/spanish/newsroom/news/2003/13201-es.html

FORESIGHT UK. 2011. The future of food and farming: Challenges and choices for global sustainability. Oficina del Gobierno del Reino Unido para la Ciencia y la Innovación. Edit. Published online by Cambridge University Press.

https://doi.org/10.1017/S207863361100021X

http://www.bis.gov.uk/assets/bispartners/foresight/docs/food-and-farming/11-546-futureof-food-and-farming-report.pdf

JÁUREGUI R, Flores HL, Vásquez LOM, Sandoval R. 2012. Caracterización de la gallina de cuello desnudo (gallus domesticus nudicullis) en la región Ch'orti de Guatemala. Revista Ciencia, Tecnología y Salud. 1(2). ISSN 2409-3459

https://es.scribd.com/document/379052191/Ciencia-Tecnologia-y-Salud

JUÁREZ CA, Murillo AJA, Suárez CJC. 2008. Phenotypic appearance traits in rural poultry in municipalities of Riberal del Lago de Patzcuaro. http://www.Irrd.cipav.org.co/lrrd12/1/jua121.html

LÁZARO GC, Hernández ZJS, Vargas LS, Martínez LA, Pérez AR. 2012. Uso de caracteres morfométricos clasificación de gallinas locales. Actas Iberoamericanas de Conservación Animal. 2:109-114. ISSN 2253-9727 http://www.uco.es/conbiand/aica/templatemo_110_lin_photo/articulos/2012/Trabajo049_AICA2012.p df

MACRI M, Martínez A, Landi V, Canales A. 2019. Genetic diversity of utrerana chicken breed. Actas Iberoamericanas de Conservación Animal. 13:52-59. https://www.researchgate.net/publication/336170786

ELIEZER VM, Román P, Durán A, Velez I, Cabrera T, Cantú C, De la Cruz Colín L. 2013. Evaluación morfológica de gallinas de traspatio mexicanas (Gallus gallus domesticus). Revista Mexinana de Ciencias Pecuarias. 4(2). ISSN 2428-6698 https://cienciaspecuarias.inifap.gob.mx/index.php/Pecuarias/article/view/4484

NAVARA KJ, Anderson EM, Edwards ML. 2012. Comb size and color relate to sperm quality: A test of the phenotype-linked fertility hypothesis. Behavioral Ecology. 23(5): 1036-1041. https://doi.org/10.1093/beheco/ars068

NACIONES UNIDAS. 2015. Restablecer y conservar los recursos naturales es esencial para la seguridad alimentaria. Construyendo una visión común para la agricultura y alimentación sostenibles. FAO. México. ISBN 978-92-5-308471-5 (edición impresa) EISBN 978-92-5-308472-2 (PDF). http://www.fao.org/3/i3940s/i3940s.pdf 
PYM R. 2013. Genética y cría de aves de corral en los países en desarrollo en los países en desarrollo. Revisión del Desarrollo Avícola. (FAO). Australia.

http://www.fao.org/3/al725s/al725s00.pdf

REVELO HA., Valenzuela MR, Álvarez LA. 2017. Caracterización morfológica de la gallina criolla del pacífico colombiano en comunidades afro, indígenas y campesinas. Actas Iberoamericanas de Conservación Animal. 10:216-221. https://www.cabdirect.org/cabdirect/abstract/20183221745

SONAIYA E, Branckaert, R, Gueye, E. 1999. Research and development options for family poultry. Primera conferencia electrónica sobre avicultura familiar Red Internacional para el Desarrollo de la Avicultura Familar (RIDAF / Organización de las Naciones Unidas para la Alimentación y la Agricultura (FAO). http://www.fao.org/3/i3531s/i3531s.pdf

TOVAR J, Narváez S, Takahashi S. 2014. Bases for the Colombian Gallus gallus domesticus (phasianidae) conservation in the department of caldas. Boletín Científico. Centro de Museos. Museo de Historia Natural. 18(1)112-122. https://www.researchgate.net/publication/287076302

VALENCIA N. 2009. La gallina criolla Colombiana. Universidad Nacional de Colombia. Facultad de Ciencias Agropecuarias. Colombia, Bogotá. ISBN: 978-958-8095-56-1 https://xdoc.mx/documents/la-gallina-criolla-universidad-nacional-de-colombia$5 \mathrm{e} 5 \mathrm{acb} 77 \mathrm{~b} 54 \mathrm{eb}$

VAN HG, Vandermeulen V, Mettepenningen E, Verspecht A. 2007. Multifunctionality of agriculture: a review of definitions, evidence and instruments. Living Reviews in Landscape research. 1:1-38. ISSN 1863-7329

http://rrr.landscapeonline.de/Articles//rlr-2007-3/download/Irlr-2007-3Color.pdf

VILLACís RG, Escudero SG, Cueva CF, Luzuriaga NA. 2016. Características Morfométricas de las Gallinas Criollas de Comunidades Rurales del Sur del Ecuador. Revista de Investigaciones Veterinarias Del Perú. 27(2). https://doi.org/10.15381/rivep.v27i2.11639

WHEELER T, Von BJ. 2013. Climate change impacts on global food security. Science. 341(6145):508-513. https://doi.org/10.1126/science.1239402 https://pubmed.ncbi.nlm.nih.gov/23908229/ 